\title{
Plasmodium vivax malaria: related factors to severity in the State of Maranhão, Brazil
}

\author{
Camila Cristina Bastos Silva Raposo ${ }^{[1]}$, João Barberino Santos ${ }^{[2]}$, \\ Gisele Maria Campelo dos Santos ${ }^{[3]}$, Eloísa da Graça do Rosário Gonçalves ${ }^{[1],[4]}$ \\ and Antonio Rafael da Silva ${ }^{[1],[4]}$
}

[1]. Centro de Referência em Doenças Infecciosas e Parasitárias, Departamento de Patologia, Universidade Federal do Maranhão, São Luis, MA. [2]. Núcleo de Medicina Tropical, Universidade de Brasília, Brasília, DF. [3]. Curso de Graduação em Medicina, Universidade Federal do Maranhão, São Luis, MA. [4]. Programa de Pós-Graduação em Saúde e Ambiente, Universidade Federal do Maranhão, São Luis, MA.

\begin{abstract}
Introduction: Malaria caused by Plasmodium vivax species has shown signs of severity, recorded with increasing frequency in the medical literature. This study aimed to characterize the signs of severe malaria by Plasmodium vivax in the State of Maranhão, Brazil. Methods: A descriptive cohort study of patients assisted in the field and a historical and concurrent study of a series of cases among hospitalized patients were undertaken to identify the clinical and laboratory signs of severity. Results: A total of 153 patients were included in the study, 13 of whom were hospitalized. Males made up the majority, numbering 103 (67.3\%). The age of the patients ranged from 10 to 70 years, $92.2 \%$ were natives of the State of Maranhão, and $65 \%$ of the patients had had malaria before. The average time elapsed between symptom onset and diagnosis among outpatients was three days, while among hospitalized patients this average reached 15.5 days, a statistically significant difference $(p=0.001)$. The parasitemia ranged from 500 to 10,000 parasites $/ \mu 1$ in $92.8 \%$ of cases. The clinical and laboratory manifestations of severity were vomiting and diarrhea, jaundice, drowsiness, mental confusion, seizures, loss of consciousness, agitation, bleeding, pale skin, coughing and dyspnea, thrombocytopenia, anemia, elevation of nitrogenous compounds, and elevated transaminases and bilirubin. Conclusions: The monitoring of malaria patients with Plasmodium vivax showed the possibility of aggravation, the intensity of which varied in different circumstances, especially the interval time between falling ill and diagnostic confirmation.
\end{abstract}

Keywords: Malaria. Severity. Plasmodium vivax. State of Maranhão.

\section{INTRODUCTION}

Malaria is one of the most important diseases that affect humans, occurring in all tropical regions of the planet and in more than 109 countries. It is one of the major causes of death from infectious diseases, resulting in more than 300 million clinical cases and approximately one million deaths per year ${ }^{1}$. In Brazil, the incidence of malaria is concentrated in nine States of the Legal Amazon (Acre, Amazonas, Amapá, Rondônia, Roraima, Pará, Tocantins, Maranhão and Mato Grosso) and represents the main endemic disease in the State of Maranhão².

A systematic reduction in the number of malaria cases has been observed in the State of Maranhão since 2000, when an intensified program to control malaria in the Amazon Region was implemented. In 2005 a total of 9,110 cases were diagnosed, of which 7,352 (80.7\%) were by Plasmodium vivax ${ }^{3}$. In the following years this tendency continued, reaching a total of 3,904 cases in 2010, with 3,000 (76.8\%) by Plasmodium vivax ${ }^{4}$.

There is little information about the severity and possible related deaths from malaria by Plasmodium vivax, which

Address to: Dr. Antonio Rafael da Silva. Centro de Referência em Doenças Infecciosas e Parasitárias/Depto. de Patologia/UFMA. Praça Madre Deus 02, Térreo, Bairro Madre Deus, 65025-560 São Luis, MA, Brasil.

Phone: 5598 3221-0270

e-mail: credip@ufma.br

Received in 09/07/2011

Accepted in 30/09/2011 usually manifests as a benign disease. Atypical manifestations and severe forms, however, have been registered and are characterized in particular by thrombocytopenia, jaundice, changes in level of consciousness, and severe anemia ${ }^{5-10}$. These events warn that more accurate observations of the disease should be made, especially in geographical areas where the species is predominant.

\section{METHODS}

Descriptive study of malaria cases with manifestations of severity assisted at ambulatory, from January to October 2005, in Buriticupu, State of Maranhão, Brazil

Located in the western region of the state, the municipality of Buriticupu integrates the administrative region of Açailândia. As an old area of agricultural settling, it occupies an area of $2,719 \mathrm{~km}^{2}$ consisting of equatorial forest, in transition with other ecosystems. The population is composed of 65,237 inhabitants $^{11}$, and agriculture and wood extraction are the main economic activities. The municipality counts on the health service of the Universidade Federal do Maranhão, which also attends to patients from other municipalities.

In 2005 a total of 1,574 examinations were performed for malaria diagnosis. This resulted in 332 positive cases, of which 292 were for Plasmodium vivax. Of this total, only 33 were autochthonous from the municipality. The others originated from other cities, states, and countries.

Historical and concurrent study from a series of cases with clinical and laboratorial manifestations of severity in patients hospitalized 
in public and private general hospitals in São Luis, capital of State of Maranhão, Brazil, from January 1999 to December 2008.

Located in the western part of the Island of São Luis, the municipality of São Luis occupies an area of $831,700 \mathrm{~km}^{2}$ and has a population of 966,989 inhabitants ${ }^{11}$. Patients with malaria were attended to by members of our team who routinely answer the calls from those care centers. Their clinical and laboratorial data were registered in specific form.

Inclusion criteria to the two phases of study were patients older than two years old and with a definite diagnosis of monoinfection by Plasmodium vivax malaria. Those with mixed infection, pregnant women, and patients with recognized chronic degenerative diseases and with clinical and/or laboratorial evidence of co-morbidities were excluded.

To investigate possible co-morbidities a detailed review of the medical records of all patients that had been attended to in Buriticupu was performed. Moreover, for inpatients, hepatitis serology was applied to those presenting jaundice. Other specific exams (dengue, kala-azar, enteric (typhoid) fever, and cytomegalovirus serology and blood culture) were performed according to the particular situation.

Parasitological diagnosis was done by the technique of thick blood film, stained using Giemsa and examined under a light microscope with immersion objective increases from 750 to 1,000 times. To quantify the parasitemia a semi-quantitative classification of parasitemia was used, as proposed by Walker ${ }^{12}$.

Since there are no official criteria of severe malaria by Plasmodium vivax, the severity of the clinical presentation in this study was established from the classification of Alecrim ${ }^{6}$, as modified: I) Classical malaria: classic signs and symptoms of malaria such as fever (axillary temperature $>37.5^{\circ} \mathrm{C}$ ), chills, sweating, headache, vomiting, hepatomegaly and/or splenomegaly; II) Severe malaria: signs and symptoms of malaria, associated with one or more of the following laboratory and clinical complications: jaundice (total bilirubin $>2 \mathrm{mg} / \mathrm{dL}$ ), anemia (hematocrit $<30 \%$ ), seizures, hypoglycemia (blood glucose $<60 \mathrm{mg} / \mathrm{dL}$ ), thrombocytopenia (platelets $<100,000 / \mathrm{mm}^{3}$ ), bleeding, coma, shock, hemoglobinuric fever, renal failure, splenic rupture, pulmonary disorders.

\section{Statistical analysis}

For the statistical analysis, the chi-square test was used or categorical variables and Fisher's exact test was used when the frequency was less than five elements. To compare the parasitemia level and severity manifestations the parasitemia classification proposed by Alecrim ${ }^{6}$, as modified, was considered. Test of hypothesis to evaluate equality of means of days between falling ill and diagnostic confirmation of patients in ambulatory care and those who were hospitalized was employed, using distribution $t$ of Student. For evaluating statistical significance a $p$ value $<0.05$ was considered.

\section{Ethical considerations}

The research protocol, under registration 021/2005, was approved by the Ethics Committee in Human Research, Faculty of Medicine, University of Brasília. The protocol meets the requirements of the National Council Health.

\section{RESULTS}

\section{Study of patients assisted in ambulatory care}

We included 140 patients in the field study according to inclusion criteria, i.e. with manifestation of severity. This represented $1.9 \%$ of the total number of Plasmodium vivax malaria in the State of Maranhão in $2005^{3}$.

The majority of them were male, numbering 94 (67\%). The patients' ages ranged from 10 to 70 years, with $102(73.2 \%)$ over 15 years. In the period of the study there was no register of patients less than 10 years old presenting criteria for severe malaria.

Autochthonous cases of Maranhão totaled 122 (87.1\%), coming from the municipalities of Buriticupu, Bom Jardim, Bom Jesus das Selvas, Alto Alegre do Pindaré, and Santa Luzia. Imported cases from other states or countries accounted for 11 (7.8\%), coming from French Guyana, Suriname, and the State of Pará. The place of transmission could not be identified in 7 $(5 \%)$ patients. Forty-three $(30.7 \%)$ patients had malaria for the first time, seventy-one (50.7\%) for the second time, $20(14.2 \%)$ for the third time, and six $(4.3 \%)$ for more than the third time. The parasitemia of $130(92.8 \%)$ patients did not exceed 10,000 parasites $/ \mu l$ at the time of their diagnostic confirmation. Among the other 10 patients, only one had over 100,000 parasites/ $\mu 1$ of blood. Considering the patients with primary infection, 38 $(88.3 \%)$ had less than 10,000 parasites/ $\mu$ l. Only $5(11.6 \%)$ in this group of patients presented parasitemia higher than 10,000 parasites $/ \mu 1$. Among those who had the disease for more than once, $91(93.8 \%)$ had parasitemia less than $10,000 / \mu 1$, while in five $(5.1 \%)$ the parasitemia was higher than $10,000 / \mu 1$. The statistical analysis showed no statistically significant difference between the variables of primary infection and parasitemia $(p=0.176)$.

The maximum time elapsed between the onset of symptoms and the parasitological confirmation of diagnosis was 10 days, with an average of three days. For 60 (42.8\%) patients, the elapsed time was 48 hours, and on this occasion $51(36.4 \%)$ patients already had parasitemia between 500 and 10,000 parasites/ $\mu 1$. A comparison between the time shorter or longer than 48 hours and the levels of parasitemia presented by the patients $\left(<10,000\right.$ and $\geq 10,000$ parasites $\left./ \mathrm{mm}^{3}\right)$ showed no statistically significant association between these variables $(p=0.636)$. The most frequent symptoms presented by patients were fever $(100 \%)$, chills $(99.3 \%)$, headache $(99.3 \%)$, and sweating (86.4\%). Among the manifestations of severity in this group of patients were gastrointestinal disorders, such as vomiting or diarrhea in 26 (18.5\%), and jaundice in $3(2.1 \%)$ patients. As for neurological disorders, the symptoms were agitation in $2(1.4 \%)$, drowsiness in 2 $(1.4 \%)$, mental confusion in $1(0.7 \%)$, loss of consciousness in $2(1.4 \%)$, and seizures in $2(1.4 \%)$. Nine $(6.4 \%)$ people had bleeding and 122 (87\%) had cutaneous-mucosal pallor. With regard to respiratory disorders, $23(16.4 \%)$ of the patients reported cough and $4(2.9 \%)$ reported having had shortness of breath.

The association between the signs and symptoms of severity and the level of parasitemia was statistically significant in this sample, in the cases of mental confusion and agitation, while the variable bleeding showed a value of $p$ very close to the considered significant value (Table 1).

Taking into account the average time elapsed from the onset of symptoms to the parasitological diagnosis (3 days), and 
TABLE 1 -Association between the severity of signs and symptoms and parasitemia reported by patients with malaria by Plasmodium vivax, assisted in the ambulatory, State of Maranhão, Brazil, 2005-2008.

\begin{tabular}{|c|c|c|c|c|c|c|}
\hline \multirow[b]{3}{*}{ Signs and symptoms } & \multicolumn{4}{|c|}{ Parasitemia } & & \\
\hline & \multicolumn{2}{|c|}{$\leq 10,000(n=130)$} & \multicolumn{2}{|c|}{$>10,000(n=10)$} & \multicolumn{2}{|c|}{ Total } \\
\hline & $\mathrm{n}$ & $\%$ & $\mathrm{n}$ & $\%$ & n & $\mathbf{P}$ \\
\hline Vomiting/diarrhea & 26 & 20.0 & 0 & 0.0 & 26 & 0.117 \\
\hline Jaundice & 3 & 2.3 & 0 & 0.0 & 3 & 0.627 \\
\hline Drowsiness & 2 & 1.5 & 0 & 0.0 & 2 & 0.693 \\
\hline Mental confusion & 0 & 0.0 & 1 & 10.0 & 1 & $<0.001$ \\
\hline Convulsion & 2 & 1.5 & 0 & 0.0 & 2 & 0.693 \\
\hline Loss of consciousness & 2 & 1.5 & 0 & 0.0 & 2 & 0.693 \\
\hline Agitation & 1 & 0.8 & 1 & 10.0 & 2 & 0.018 \\
\hline Bleeding & 7 & 5.4 & 2 & 20.0 & 9 & 0.069 \\
\hline Pallor & 114 & 87.7 & 8 & 80.0 & 122 & 0.484 \\
\hline Dyspnea & 4 & 3.1 & 0 & 0.0 & 4 & 0.574 \\
\hline Cough & 22 & 16.9 & 1 & 10.0 & 23 & 0.569 \\
\hline
\end{tabular}

TABLE 2 - Association between the signs and symptoms of severity and the time elapsed between the onset of symptoms and diagnosis of patients with malaria by Plasmodium vivax, assisted in the field, State of Maranhão, Brazil, 2005-2008.

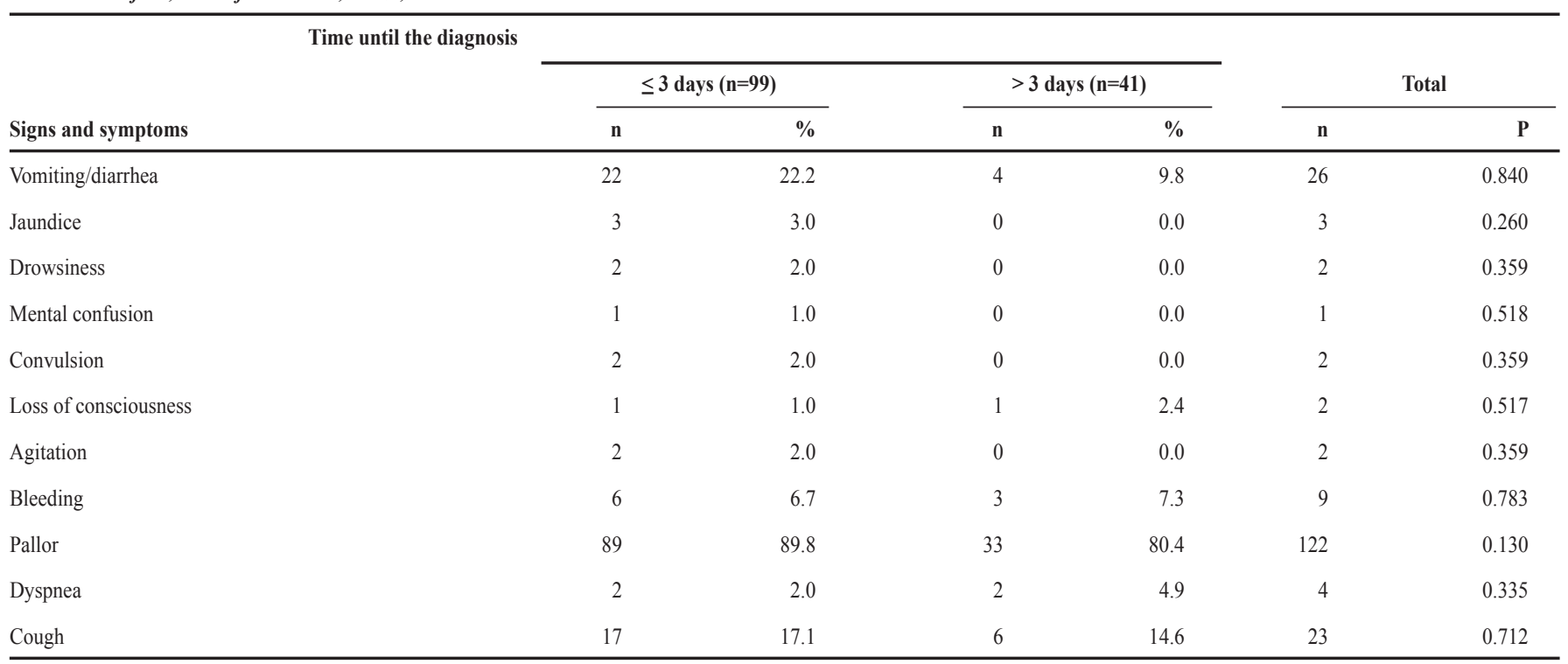

relating it to the signs and symptoms of severity presented by patients, it was not possible to establish a statistically significant association for any variable studied in this group of patients (Table 2).

Regarding the number of malarial affections with symptoms and signs of severity, it was observed that the symptoms that may denote complication were not significantly associated with the primary infection (Table 3). The variable of diarrhea showed a $p$ value to closer to the considered statistically significant value.

\section{Study of hospitalized patients}

We studied 13 patients admitted to hospitals in São Luis from 1999 to 2008. Twelve patients came from the following municipalities of Maranhão: São Luis, São José de Ribamar, Itapecuru, Grajaú, São Bento, and Icatú. One patient got the infection in Pindaí, State of Amapá. Tables $\mathbf{4}$ and $\mathbf{5}$ present their clinical and laboratory data. The hepatitis serology performed on patients with jaundice was negative. Others exams, such as dengue, kala-azar, enteric (typhoid) fever, and cytomegalovirus serology and blood culture, were performed according to particular clinical conditions and were negative as well.

The age of these patients ranged from 10 to 58 years. All of them had primary infection and had time intervals between the disease and diagnostic confirmation from 6 to 41 days (mean 15.5 days). When the hypothesis of equality of this average was tested against the average time between the diagnosis and confirmation of the disease seen in ambulatory patients ( 3 days), the difference was found to be significant ( $p=0.001$ ). The parasite count showed that only one patient had parasitemia higher than $10,000 / \mu 1$. 
TABLE 3 - Association between the signs and symptoms of severity and the number of malaria infections in patients with Plasmodium vivax malaria, assisted in the field, State of Maranhão, Brazil, 2005-2008.

\begin{tabular}{|c|c|c|c|c|c|c|}
\hline \multirow[b]{3}{*}{ Signs and symptoms } & \multicolumn{6}{|c|}{ Number of malaria infections } \\
\hline & \multicolumn{2}{|c|}{$\begin{array}{c}\text { primary } \\
\text { infection }(n=43)\end{array}$} & \multirow{2}{*}{$\begin{array}{c}\text { multi-infection } \\
(\mathrm{n}=96)\end{array}$} & \multirow[b]{2}{*}{$\%$} & \multirow[b]{2}{*}{ Total } & \multirow[b]{2}{*}{$\mathbf{p}$} \\
\hline & n & $\%$ & & & & \\
\hline Vomiting/diarrhea & 4 & 9.3 & 22 & 22.9 & 26 & 0.059 \\
\hline Mental confusion & 1 & 2.3 & 0 & 0.0 & 1 & 0.134 \\
\hline Convulsion & 1 & 2.3 & 1 & 1.0 & 2 & 0.557 \\
\hline Loss of consciousness & 1 & 2.3 & 1 & 1.0 & 2 & 0.557 \\
\hline Agitation & 0 & 0.0 & 2 & 2.1 & 2 & 0.340 \\
\hline Dyspnea & 2 & 4.7 & 2 & 2.1 & 4 & 0.225 \\
\hline Cough & 10 & 23.2 & 12 & 12.5 & 22 & 0.082 \\
\hline
\end{tabular}

TABLE 4 - Severe malaria caused by Plasmodium vivax in hospitalized patients, São Luis, State of Maranhão, Brazil, from 1999 to 2008.

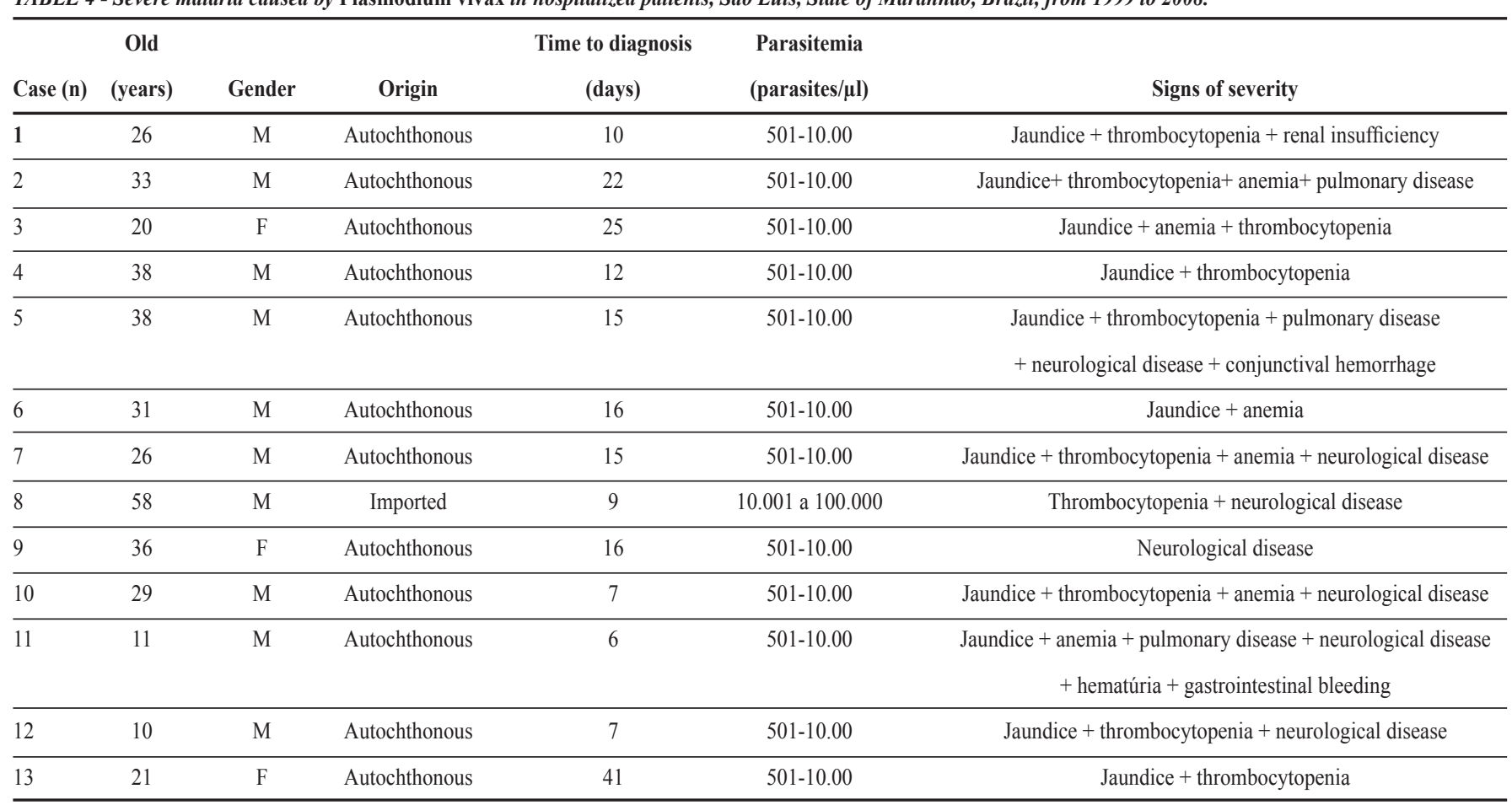

M: male; F: female.

Among the identified signs of severity, jaundice was the most common, with one patient having developed cholecystitis without lithiasis. The neurological changes identified were dizziness, drowsiness, mental confusion, and loss of consciousness; the respiratory symptoms were dyspnea and pulmonary infiltrates seen on chest radiography.

The most frequent laboratorial complication was thrombocytopenia, with three (23\%) patients having less than 50,000 platelets $/ \mu 1$ and two of these patients having conjunctival hemorrhage, hematuria, and gastrointestinal bleeding. Other manifestations of severity were anemia with hemoglobin levels below $10 \mathrm{~g} \%$, hiperbirrubinemia above $5 \mathrm{mg} / \mathrm{dL}$, elevated transaminases, and elevated nitrogenous compounds.

All patients in the study, with the exception of a hospitalized patient who received artemisinin because of a gastrointestinal bleeding, were treated with chloroquine associated with primaquine and presented a good clinical response and negative parasitemia in the second day of treatment. There were no deaths in the follow-up. 
TABLE 5 - Laboratory tests results of patients hospitalized with severe malaria by Plasmodium vivax, São Luis, State of Maranhão, Brazil, from 1999 to 2008.

\begin{tabular}{|c|c|c|c|c|c|c|c|c|c|c|}
\hline Case (n) & $\mathrm{Hg}$ & Ht & Platelets & AST & ALT & $\mathbf{U}$ & $\mathrm{Cr}$ & TB & DB & IB \\
\hline 2 & 9 & 26 & 49,800 & 41 & 38 & 20 & 0.4 & 10.6 & 5.3 & 5.3 \\
\hline 3 & 9 & 26 & 72,000 & 58 & 18 & 19 & 1.2 & 2.9 & 1.7 & 1.2 \\
\hline 4 & 10.6 & 30.8 & 18,000 & 84 & 67 & 64 & 1.15 & 19.23 & 11.28 & 7.95 \\
\hline 7 & 6.8 & 19.2 & 59,000 & 125 & 190 & - & 1.2 & 15.2 & 11 & 4.2 \\
\hline 8 & 12.4 & 37.3 & 72,000 & 83 & 58 & 84 & 1 & 2.88 & 2.05 & 0.83 \\
\hline 9 & 12.4 & 38.9 & 128,000 & - & - & - & - & - & - & - \\
\hline 10 & 10.1 & 31.7 & 78,000 & 113 & 66 & 25 & 0.7 & 2.9 & 0.8 & 1.6 \\
\hline 13 & 5.5 & 16 & 54,000 & - & - & - & - & - & - & - \\
\hline
\end{tabular}

Hg: hemoglobin; Ht: hematocrit; AST: aspartate aminotransferase; ALT: alanine aminotransferase; U: urea; Cr: creatinine; TB: total bilirubin; DB: direct bilirubin; IB: indirect bilirubin.

\section{DISCUSSION}

The study presents some limitations, because it was composed of a retrospective part developed from data of patients attended in the field. At the beginning, the authors had difficulty defining the criteria of severe malaria by Plasmodium vivax, since there are no official criteria defined to this species. Thus, although the criteria of severity from Alecrim ${ }^{6}$ have not been published, they were adopted in this study considering the author first described such severe manifestations in the Brazilian Amazon.

For the same reason it was not possible to apply polymerase chain reaction, which would allow the exclusion of possible mixed infection. However, the good clinical and parasitic response to treatment with chloroquine exhibited by patients reinforced the diagnoses of infection by Plasmodium vivax.

Plasmodium vivax malaria, predominant in the State of Maranhão, is commonly considered a benign condition ${ }^{13,14}$. However, clear signs of severity have been observed, and in some cases hospitalization is required due to medical complications, such as those that occurred in the 13 cases in this study.

Almost all the patients initially showed the classic clinical presentation of malaria, following the trend observed in endemic regions. However, even if this statement is true for these regions, atypical manifestations denoting severity have been observed in an increasing way ${ }^{6,8,15}$. Signs and symptoms, such as vomiting, diarrhea, jaundice, drowsiness, mental confusion, seizures, loss of consciousness, bleeding, and dyspnea, that registered in a significant percentage of patients confirm these findings.

Anemia, described as one of the major aggravations of malaria, is usually recorded as more severe in children and pregnant women with malaria by Plasmodium falciparum ${ }^{16,17}$.
It was not possible to confirm this observation in this study, since there were no children less than 10 years old with severity manifestations while pregnant women were excluded.

However, as can be seen in the clinical and laboratory data of 13 hospitalized patients, anemia can become a serious condition in Plasmodium vivax malaria, resulting in the need for blood transfusion, which occurred with four of our patients. The low frequency of neurological disorders among patients seen in the ambulatory contrasts with the high $(58 \%)$ proportion among those hospitalized. Similarly, the occurrence of alterations in the respiratory, liver, and kidney functions are consistent with data reported by other authors in relation to malaria by Plasmodium vivax ${ }^{8,18,19}$. Noteworthy is the finding of jaundice in $2.1 \%$ of patients treated in ambulatory and in $58 \%$ of hospitalized patients, a sign that can lead to misdiagnosis, as observed in some patients who received an initial diagnosis of hepatitis. Serology and other laboratorial exams that proved negative excluded this diagnosis and other conditions. Moreover, with the specific treatment of malaria there was a normalization of serum bilirubin levels in the following days after the introduction of anti-malarial drugs.

Mild to moderate thrombocytopenia often occurs in malaria ${ }^{6,9}$, although only rarely manifests itself by spontaneous hemorrhages. In the present study the laboratory abnormality was documented more frequently among hospitalized patients. It was probably present in some patients treated in ambulatory. As verified by other authors ${ }^{6,9}$, the platelet count also normalized right after treatment. The lack of correct diagnosis and lack of understanding by health professionals that malaria by Plasmodium vivax can develop with such manifestations may lead to the performance of inappropriate exams and treatment.

Patients with primary infection, as expected, showed higher parasitemia, presumably with the absence of acquired immunity in previous contact with Plasmodium sp. It was observed, however, 
that although these patients presented higher levels of parasitemia, this was not statistically significant and did not reflect the severity of the disease in these patients. Parasite density has been identified as a sign of bad prognosis ${ }^{8}$. In this study, there was no statistical relation between the level of parasitemia and the severity of clinical manifestations. In the analysis of the manifestations of severity, only mental confusion and agitation appear to be associated with parasitemia higher than 10,000 parasites/ $\mu 1$.

The delay in confirming the diagnosis was not reflected in high parasitemia. However, as can be seen in the study of hospitalized patients, the delay in establishing the diagnosis and beginning the treatment had negative repercussions and seems to have been decisive in the development and intensity of severe manifestations. A good clinical response, parasitologic clearance in the first two days of treatment, and no occurrence of deaths show that complications are reversible with proper treatment.

Data on parasitemia at day 28 after treatment were not available for all the patients and thus did not allow an evaluation of the possible development of in vivo chloroquine resistance, in line with other studies in the Brazilian Amazon ${ }^{20}$. Prospective studies need to be developed in the area for a better understanding of the issue.

The severity of Plasmodium vivax malaria may be associated with the circulating variant of the species in certain regions ${ }^{21}$. In the State of Maranhão knowledge of the genetic variations of Plasmodium vivax is incipient ${ }^{22}$, indicating the need for more research in this area for a clearer definition of this association. The National Plan for Malaria Control establishes early diagnosis and treatment as one of its main goals, toward reducing severity, mortality and disease transmission. It has been verified that although the State of Maranhão has shown a systematic reduction in the number of malaria cases in recent years ${ }^{2}$, it still has difficulties in diagnosing the total number of cases within $48 \mathrm{~h}$ of onset of symptoms, which could reduce the development of complications.

\section{ACKNOWLEDGMENTS}

We gratefully acknowledge Dr. Vanize Macedo in memoriam for her contribution in the initial part of this study and Dr. Elizabeth Carmem Duarte and Dr. Ana Nogales (University of Brasília) for statistical analysis.

\section{CONFLICT OF INTEREST}

The authors declare that there is no conflict of interest.

\section{FINANCIAL SUPPORT}

Coordenação de Aperfeiçoamento de Pessoal de Nível Superior (CAPES).

\section{REFERENCES}

1. Ministério da Saúde. Secretaria de Vigilância em Saúde. Guia de Vigilância Epidemiológica. Série A. Normas e Manuais Técnicos. Caderno 10. $7^{\mathrm{a}}$ ed. Brasília: Ministério da Saúde; 2009.
2. Silva AR, Fernandes JMC, Rodrigues TA, Santos HJ, Cavalheiro NNM, Guimarães MC, et al. Controle da malária no Estado do Maranhão. Rev Soc Bras Med Trop 2009; 42:318-324.

3. Ministério da Saúde. Secretaria de Vigilância em Saúde. Sistema Nacional de Vigilância em Saúde: relatório de situação: Maranhão. Série C. Projetos, Programas e Relatórios. 2a . ed Brasília: Ministério da Saúde; 2006.

4. Sistema de Informação de Vigilância Epidemiológica (SIVEP). Malária. Notificação de casos [Internet]. Brasília: Ministério da Saúde; 2011. [Cited 2012 August 3]. Available from: www.ses.gov.br/malária/.

5. Islam N, Qamruddin K. Unusual complications in benign tertian malaria. Trop Geograph Med 1995; 47:141-143.

6. Alecrim MGC. Estudo clínico, resistência e polimorfismo parasitário na malaria pelo Plasmodium vivax, em Manaus - AM. [Doctors Thesis]. [Brasília]: Universidade de Brasília; 2000. p.177.

7. Mohapatra MK, Padhiary KN, Mishar DP. Sethy. Atypical manifestations of Plasmodium vivax malaria. Indian J Malariol 2002; 39:18-25.

8. Echeweri M, TobinA,Alvarez G, Carmona J, Blair S. Clinical and laboratory findings of Plasmodium vivax malaria in Colômbia, 2001. Rev Inst Med Trop Sao Paulo 2003; 45:29-34.

9. Lacerda MVG, Alexandre MAA, Santos PD, Alecrim WD, Alecrim MGC. Idiopathic thrombocytopenic purpura due to vivax malaria in the Brazilian Amazon. Acta Trop 2004; 90:187-190.

10. Rodrigues-Morales AJ, Sánchez E, Vargas M, Piccolo C, Colina R, Arria M. Anemia and thrombocytopenia in chlidren with Plasmodium vivax malaria. $\mathrm{J}$ Trop Pediatrics 2005; 24:32.

11. Instituto Brasileiro de Geografia e Estatística (IBGE). Censo 2010 [Internet]. Dados Maranhão. [Cited 2012 August 3] Available from: http://www.censo2010. ibge.gov.br/dados_divulgados/index.php?uf=21/.

12. Ministério da Saúde. Secretaria de Vigilância em Saúde. Manual de diagnóstico laboratorial da malária. Série A. Normas e Manuais Técnicos. Brasília: Ministério da Saúde; 2005.

13. Ribeiro MCT, Gonçalves EGR, Tauil PL, Silva AR. Aspectos epidemiológicos de um foco de malária no município de São Luis, MA. Rev Soc Bras Med Trop 2005; 38:272-274.

14. Silva AR, Tauil PL, Bastos Júnior JL, Matos WB, Costa EAP, Gonçalves EGR. Aspectos da transmissão focal de malária na Ilha de São Luis, Maranhão. Rev Soc Bras Med Trop 2006; 39:250-254.

15. Oh MD, Shin H, Shin D, Kim U, Lee S, Kim N, et al. Clinical aspects of vivax malaria. Am J Trop Med Hyg 2001; 65:143-146.

16. Marsh KM, Crawle J, Peshu N. The pathogenesis of severe malaria in african children. Ann Trop Med Parasitol 1996; 90:395-402.

17. Singh H, Parakh A, Basu S, Rath B. Plasmodium vivax malaria: is it actually benign? J Infect Public Health 2011; 4:91-95.

18. Anstey NM, Jacups SP, Cain T, Pearson T, Ziezing PJ, Fisher DA, et al. Pulmonary manifestations of uncomplicated falciparum ans vivax malaria: cought, smallairways obstruction, impaired gas transfer and increased pulmonary phagocytic activity. J Infect Dis 2002; 185:1326-1334.

19. Maheshwari A, Singh AK, Sinha DK, Tripathi K, Prakash J. Spectrum of renal disease in malaria. J Indian Med Assoc 2004; 102:143-148.

20. Alexandre MA, Ferreira CO, Siqueira AM, Magalhães BL, Mourão MPG, Lacerda MV, et al. Severe Plasmodium vivax Malaria, Brazilian Amazon. Emerg Infect Dis 2010; 16:1611-1614.

21. Machado RLD, Povoa MM. Distribution of Plasmodium vivax variants (VK 210, VK 247 and $P$. vivax - like) in the endemic areas of the Amazon Region of Brazil and their correlation with chloroquine treatment. Trans R Soc Med Hyg 2000; 94:377-381.

22. Gonçalves EGR, Machado RLD, Santos AR, Raposo CCBS, Matos WB, Silva AR. Caracterização de genótipos de Plasmodium vivax na Ilha de São Luís, Maranhão. Rev Soc Bras Med Trop 2009; 42:315-317. 